\title{
Characteristics of Diabetic Osteopenia in KK-Ay Diabetic Mice
}

\author{
Satoshi Takagi, ${ }^{a, c}$ Toshihiro Miura, ${ }^{* a}$ Takenori Yamashita, ${ }^{b}$ Naoki Ando, ${ }^{c}$ Haruka Nakao, ${ }^{a}$ \\ Eriko Ishihara, ${ }^{a}$ and Torao Ishida ${ }^{d}$ \\ ${ }^{a}$ Department of Clinical Nutrition, Suzuka University of Medical Science; ${ }^{b}$ Department of Radiological Technology, \\ Suzuka University of Medical Science; ${ }^{d}$ Department of Acupuncture and Moxibustion, Suzuka University of Medical \\ Science; 1001-1 Kishioka, Suzuka, Mie 510-0293, Japan: and ${ }^{c}$ Takagi Project; 2-186 Sakurashinmachi, Yokkaichi, \\ Mie 512-1215, Japan. Received October 18, 2011; accepted November 24, 2011; published online December 15, 2011
}

We examined the bone mineral density (BMD) of the proximal region and the mid-diaphysis of the femur using dual energy X-ray absorption (DXA), the blood osteocalcin level and the blood glucose level every five weeks from 8 to 23 weeks old in KK-Ay diabetic mice. The BMD of the proximal region after 18 weeks old was significantly lower when compared with that at 8 weeks old $(p<0.05)$, whereas there was no significant difference in the BMD of the mid-diaphysis at each week. The BMD of the proximal region at 18 weeks old was significantly lower than that in ddY mice, used as controls $(p<0.05)$. The blood osteocalcin level at 18 weeks old was significantly lower than that at 8 weeks old and that in 18 -week-old ddY mice $(p<0.05)$. There was significant negative correlation between the blood glucose level and the BMD of the proximal region $(r=-0.64, p<0.05)$. These results suggest that type 2 diabetes exerts an influence only on spongy bone, not on cortical bone, and that the BMD in the proximal region of the femur seems to be affected by blood glucose level, parallel with the progression of diabetes, through the blood osteocalcin level. In the present study, we show the characteristics of diabetic osteopenia in KK-Ay mice, an animal model of type 2 diabetes.

Key words osteopenia; bone mineral density; type 2 diabetes; femur; KK-Ay mice

Diabetes mellitus is a metabolic disease assuming chronic hyperglycemia as its main symptom. Its major chronic complications, neuropathy, nephropathy and retinopathy, are well known and it has been shown that control of blood glucose level is important in preventing them. ${ }^{1-3)}$ Recently, in addition, diabetic osteopenia has attracted attention. There are many studies showing that diabetics have a higher risk of fractures than non-diabetics. ${ }^{4-11)}$ In type 1 diabetes mellitus, it is generally accepted that bone mineral density (BMD) decreases more than that of non-diabetics ${ }^{5,10,12-15)}$ and that the frequency of fractures increases as a result..$^{5-7,10)}$ Studies using animal models of type 1 diabetes have also shown decreased BMD. ${ }^{16-19)}$

On the other hand, several studies have shown similar $^{15,20)}$ or higher ${ }^{8,21-24)} \mathrm{BMD}$ in type 2 diabetes relative to nondiabetics, although an increased fracture risk in type 2 diabetes compared with that in non-diabetics has been reported in many studies. ${ }^{6-10,23)}$ But then we can find some other studies showing that BMD in type 2 diabetes was also reduced as well as in type 1 diabetes. ${ }^{25-30}$ ) In addition, some studies using animal models of type 2 diabetes have shown decreased BMD relative to that of non-diabetics. ${ }^{31-34}$

There are many methods of assaying BMD, such as dual energy X-ray absorption (DXA), microdensitometry, ultrasound, peripheral quantitative computed tomography (pQCT), microcomputed tomography (micro-CT) and so on. Researchers have measured BMD using various methods in various parts of the body such as the lumbar spine, femur, tibia, radius and so on in their studies. However the times the measurements were carried out are not made clear in most previous studies. Although it seems that DXA is widely used clinically to determine BMD, we rarely find it used in longitudinal studies of BMD for each of the metaphysis and diaphysis of the femur with week of age in type 2 diabetic mice. ${ }^{33)}$ Additionally it has so far been unclear when BMD changes and whether spongy or cortical bone is affected in type 2 diabetic mice.
In accordance with a change of BMD, it has been suggested that blood osteocalcin level, the biochemical osteoplastic marker, is significantly lower in both type 1 and type 2 diabetes than in non-diabetics. ${ }^{18,19,26,35-39)}$ But the time of its measurement was variable in each study and blood osteocalcin level has not been considered in its relationship with change in BMD or duration of diabetes. In the present study, we examined the BMD of the proximal region and the mid-diaphysis of the femur to clarify the characteristics of diabetic osteopenia using DXA and the relationship with blood osteocalcin or glucose level in KK-Ay mice, an animal model of type 2 diabetes.

\section{MATERIALS AND METHODS}

Animals Adult male KK-Ay mice (8 weeks old; Clea, Japan), weighing 35-40 g, were used. Under non-fasting conditions, those with blood glucose levels above $300 \mathrm{mg} / \mathrm{dL}$ were considered to be diabetic and were used in this study. Adult male ddY mice, a normal animal model, (8 weeks old; SLC, Japan), weighing $35-40 \mathrm{~g}$, were used as controls because their blood glucose levels are invariable and never change with week of age. The mice were housed individually in an air-conditioned experimental room at $22 \pm 2{ }^{\circ} \mathrm{C}$ with a $12-\mathrm{h}$ light and 12-h dark cycle. They were kept in the room for seven days with free access to food and water. The animals were tested in accordance with the Guidelines for the Care and Use of Laboratory Animals (Prime Minister's Office Directive No. $88,2006)$.

Determination of Bone Mineral Density of the Femur The BMD of the proximal region and the mid-diaphysis of the right femur in KK-Ay mice was measured using DXA with an apparatus for small animals (DICHROMA SCAN DCS-600, ALOKA, Osaka, Japan) (Fig. 1a). The mice were anesthetized by intraperitoneal injection of chloral hydrate $(400 \mathrm{mg} / \mathrm{kg})$ and the measurements were performed with extended hip and knee 


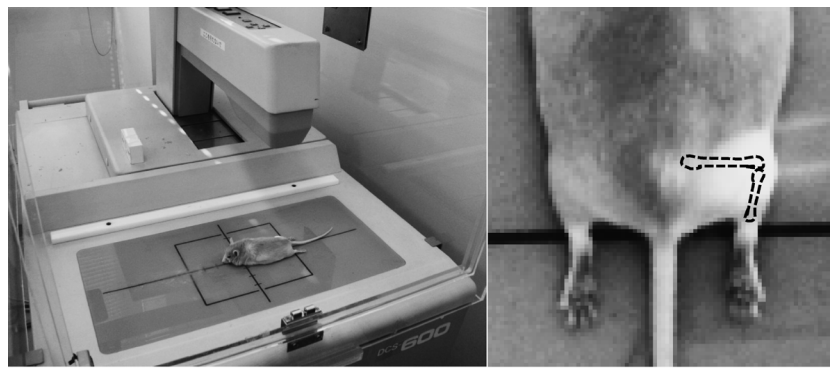

(a)

Fig. 1. Measurement of the BMD of the Femur by DXA

The BMD of the proximal region and the mid-diaphysis of the right femur in KK-Ay mice was measured using DXA (a). The mice were anesthetized by intraperitoneal injection of chloral hydrate and the measurements were made with extended hip and knee joints, in fact, with flexion of both of them (b).

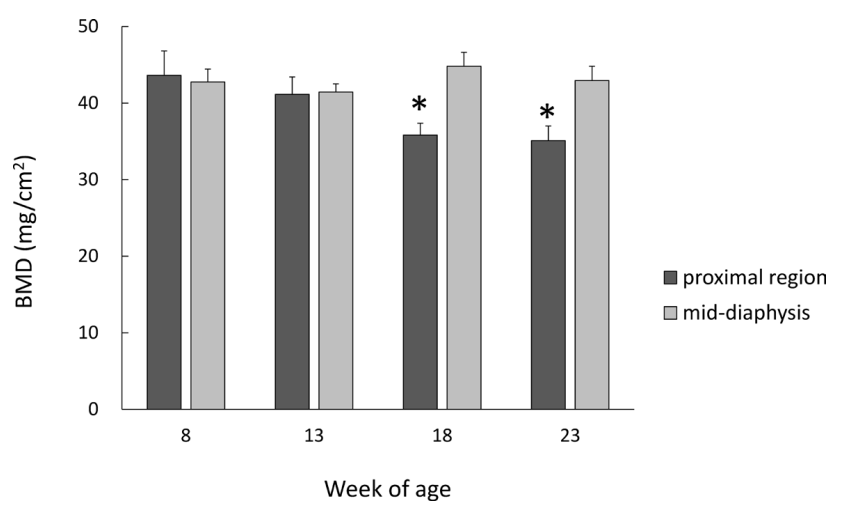

Fig. 2. The BMD of the Proximal Region and the Mid-Diaphysis of the Femur in KK-Ay Mice

The BMD of the proximal region and the mid-diaphysis of the femur in KK-Ay mice was measured every five weeks from 8 to 23 weeks old using DXA. Each value represents the mean \pm S.E.M. from 7 mice. There is a significant difference from 8 weeks old, ${ }^{*} p<0.05$

joints, in fact, with flexion of both of them (Fig. 1b), every five weeks from 8 to 23 weeks of age. All the measurements were carried out by the same radiological technologist.

Determination of Blood Osteocalcin Levels Blood samples were withdrawn from the cavernous sinus with a capillary at 8 and 18 weeks old. Blood osteocalcin levels in the animals were determined using the mouse osteocalcin EIA kit BT-470 (Biomedical Technologies Inc.).

Determination of Blood Glucose Levels Blood samples were withdrawn under non-fasting conditions every five weeks. Blood glucose levels in the animals were determined using the glucose CII-test Wako (Wako Pure Chemical Industries, Osaka, Japan), based on the glucose oxidase method. $^{40)}$

Statistical Analysis All the data were expressed as mean \pm standard error of the mean (S.E.M.). One way analysis of variance (ANOVA) followed by Tukey's honestly significant difference (HSD) test for post hoc analysis, Student's $t$ test, and Pearson's correlation test were used for the statistical analysis. Values were considered to be significantly different when the $p$ value was less than 0.05 .

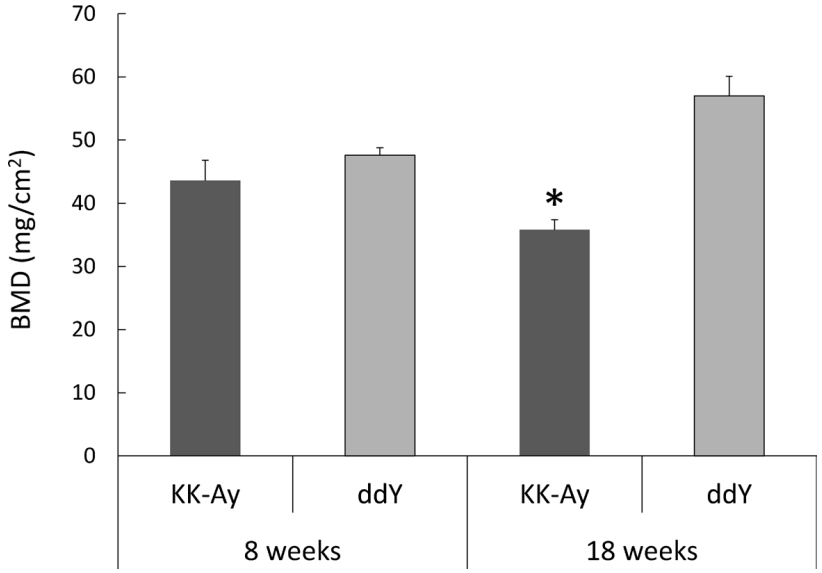

Fig. 3. The BMD of the Proximal Region of the Femur in KK-Ay and ddY Mice at 8 and 18 Weeks Old

The BMD of the proximal region of the femur in KK-Ay mice and ddY mice was measured at 8 and 18 weeks old. Each value represents the mean \pm S.E.M. from $5-7$ mice. There is a significant difference from ddY mice, ${ }^{*} p<0.05$.

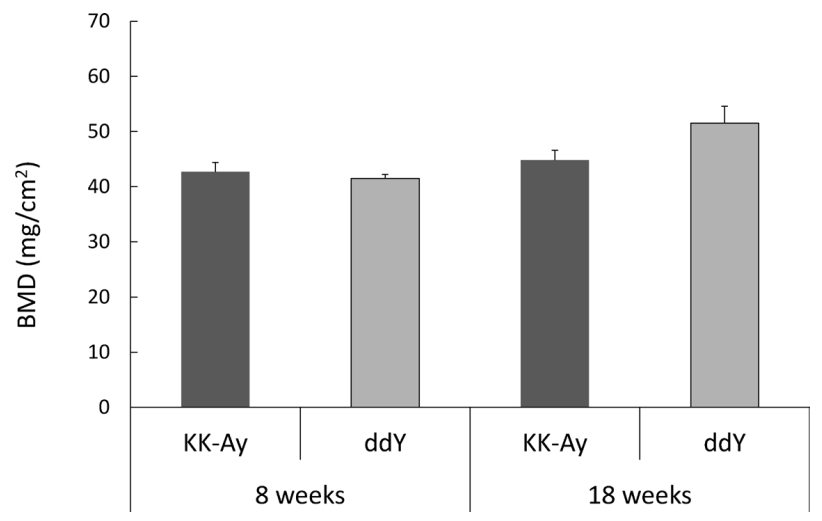

Fig. 4. The BMD of the Mid-Diaphysis of the Femur in KK-Ay and ddY Mice at 8 and 18 Weeks Old

The BMD of the mid-diaphysis of the femur in KK-Ay mice and ddY mice was measured at 8 and 18 weeks old. Each value represents the mean \pm S.E.M. from 5-7 mice.

\section{RESULTS}

Bone Mineral Density of the Femur in KK-Ay Mice Figure 2 shows the mean BMD of the proximal region and the mid-diaphysis of the femur in KK-Ay mice at each week. The BMD of the proximal region at 18 weeks and 23 weeks old was significantly lower compared with that at 8 weeks old $(p<0.05)$. There was no significant difference in the BMD of the mid-diaphysis of the femur in each week.

Figure 3 shows the mean BMD of the proximal region of the femur in KK-Ay mice in comparison with that in ddY mice at 8 and 18 weeks old. The BMD of the proximal region in KK-Ay mice at 18 weeks old was significantly lower than that in $\mathrm{ddY}$ mice $(p<0.05)\left(35.8 \pm 1.6 \mathrm{mg} / \mathrm{cm}^{2}\right.$ in KK-Ay mice, $57.0 \pm 3.1 \mathrm{mg} / \mathrm{cm}^{2}$ in ddY mice), whereas there was no significant difference between the two groups at 8 weeks old $\left(43.6 \pm 3.2 \mathrm{mg} / \mathrm{cm}^{2}\right.$ in KK-Ay mice, $47.6 \pm 1.2 \mathrm{mg} / \mathrm{cm}^{2}$ in $\mathrm{ddY}$ mice).

Figure 4 shows the mean BMD of the mid-diaphysis of the femur in KK-Ay mice in comparison with that in ddY mice at 


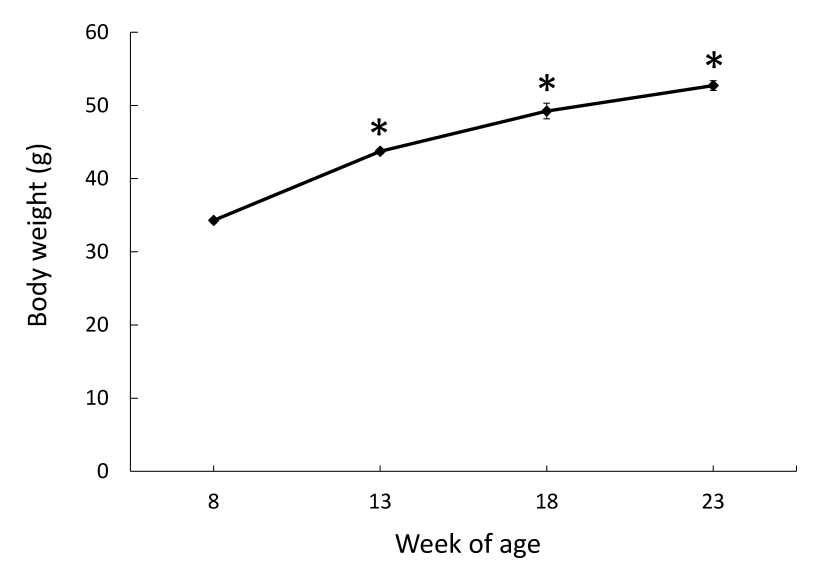

Fig. 5. The Body Weights in KK-Ay Mice

The body weights in KK-Ay mice were measured every five weeks from 8 to 23 weeks old. Each value represents the mean \pm S.E.M. from 7 mice. There is a significant difference from week to week, ${ }^{*} p<0.05$.

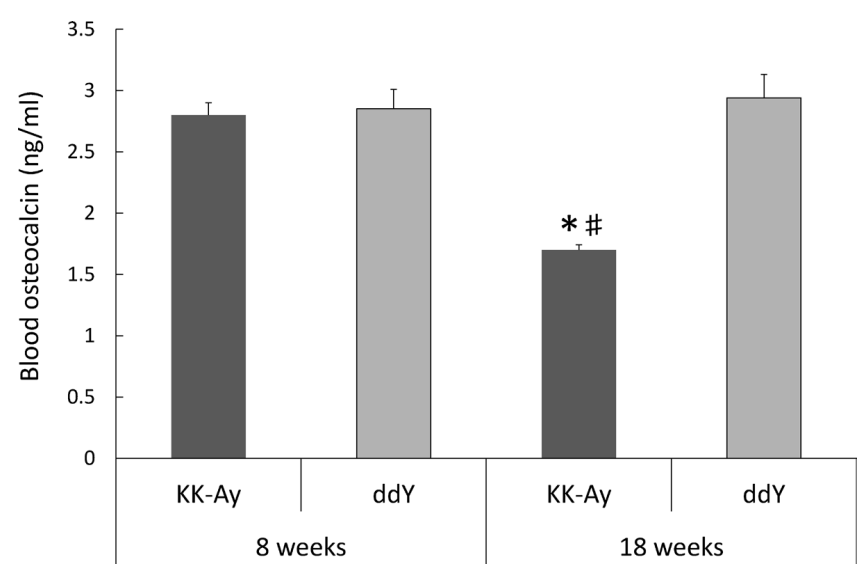

Fig. 6. Blood Osteocalcin Levels in KK-Ay and ddY Mice at 8 and 18 Weeks Old

Blood osteocalcin levels in KK-Ay mice and ddY mice were measured at 8 and 18 weeks old. Each value represents the mean \pm S.E.M. from 6 mice. There is a significant difference from ddY mice, ${ }^{*} p<0.05$. There is a significant difference from 8 weeks old, ${ }^{\#} p<0.05$.

8 and 18 weeks old. There was no significant difference between the two groups at either age.

Figure 5 shows the mean body weights at each week in KK-Ay mice. There was a significant difference from week to week $(p<0.05)$.

Blood Osteocalcin Levels in KK-Ay Mice Figure 6 shows the mean blood osteocalcin levels in KK-Ay mice and ddY mice at 8 and 18 weeks old. The blood osteocalcin level at 18 weeks in KK-Ay mice was significantly lower than that in ddY mice $(p<0.05)(1.7 \pm 0.04 \mathrm{ng} / \mathrm{mL}$ in KK-Ay mice, $2.9 \pm 0.2 \mathrm{ng} / \mathrm{mL}$ in ddY mice), whereas there was no significant difference at 8 weeks $(2.8 \pm 0.1 \mathrm{ng} / \mathrm{mL}$ in KK-Ay mice, $2.9 \pm 0.2 \mathrm{ng} / \mathrm{mL}$ in ddY mice).

Blood Glucose Levels in KK-Ay and ddY Mice Figure 7 shows the mean blood glucose levels at each week in KK-Ay and ddY mice. The blood glucose levels at 18 and 23 weeks old were significantly higher compared with those at 8 weeks old in KK-Ay mice $(p<0.05)$, whereas there was no significant difference in ddY mice in each week. The blood glucose levels at each week in KK-Ay mice were significantly higher than those in ddY mice $(p<0.05)$.

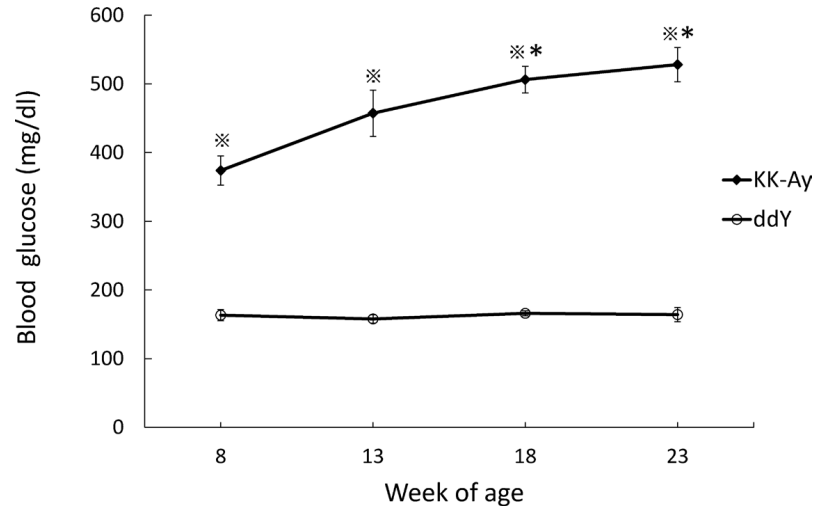

Fig. 7. Blood Glucose Levels in KK-Ay and ddY Mice

Blood glucose levels in KK-Ay and ddY mice were measured every five weeks from 8 to 23 weeks old. Each value represents the mean \pm S.E.M. from $5-7$ mice. There is a significant difference from 8 weeks old, ${ }^{*} p<0.05$. There is a significant difference from ddY mice, ${ }_{p}^{*}<0.05$.

Figure 8 shows the relationship between blood glucose level and BMD of the femur. There was a significant negative correlation between blood glucose level and BMD of the proximal region of the femur $(r=-0.64, p<0.05)$, whereas there was no significant correlation with BMD of the mid-diaphysis $(r=0.16)$.

\section{DISCUSSION}

The purpose of our study was to research osteopenia in type 2 diabetes, by considering the characteristics of change of BMD in the proximal region and the mid-diaphysis of the femur with week of age and the relationship between BMD and blood osteocalcin or glucose level using KK-Ay laboratory diabetic mice. It has been recognized that BMD of the long bones decreases in both humans and animals with type 1 diabetes, ${ }^{10,13-15,17,19)}$ and the reduction has been particularly found in trabecular bone. ${ }^{17,19)}$ On the other hand, it has not been determined whether BMD decreases or increases and whether spongy or cortical bone is affected in type 2 diabetes. Studies using DXA have shown lower BMD of the proximal region of the femur relative to non-diabetics, ${ }^{25,26)}$ whereas some other studies have shown higher BMD in type 2 diabetes. ${ }^{8,23,24)}$

Firstly, we investigated any increases or decreases in BMD of the proximal region and the mid-diaphysis of the femur with week of age using DXA. As a result, we found decreased BMD in the proximal region after 18 weeks old. It has been reported that body weight prevents bone loss because a positive correlation was found between BMD and body mass index (BMI) ${ }^{35,41,42)}$ However increase in body weight did not prevent bone loss in our study. Therefore body weight may not contribute to the prevention of bone loss in type 2 diabetes, and BMD was rather thought to be affected by the other factors.

In previous studies using experimental animal models, Lorentzon et al. $^{34)}$ found that the spongy bone area was significantly reduced on the distal femur metaphysis, and the area of cortical bone of the tibia diaphysis was also significantly smaller in $\mathrm{db} / \mathrm{db}$ mice than that in their lean litter mates. Amir et $a l .{ }^{31)}$ showed that the BMD of the distal femur was significantly reduced in spite of the duration of diabetes in Cohen diabetic rats, a non-obese model of type 2 diabetes. Kawashima 


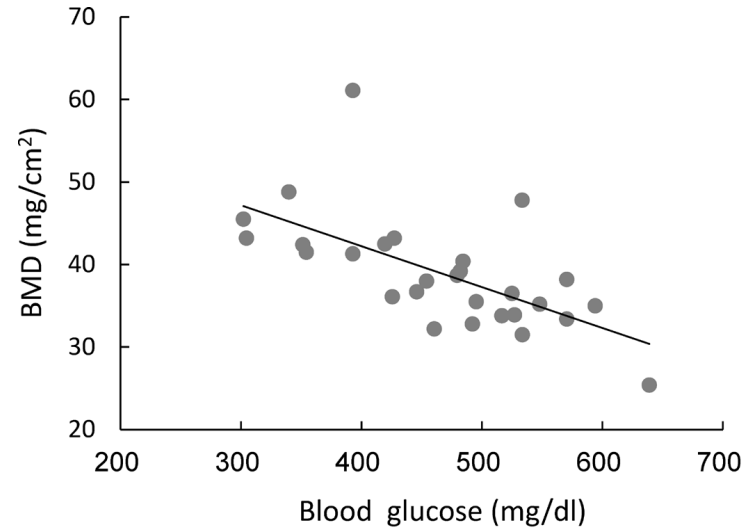

(a)

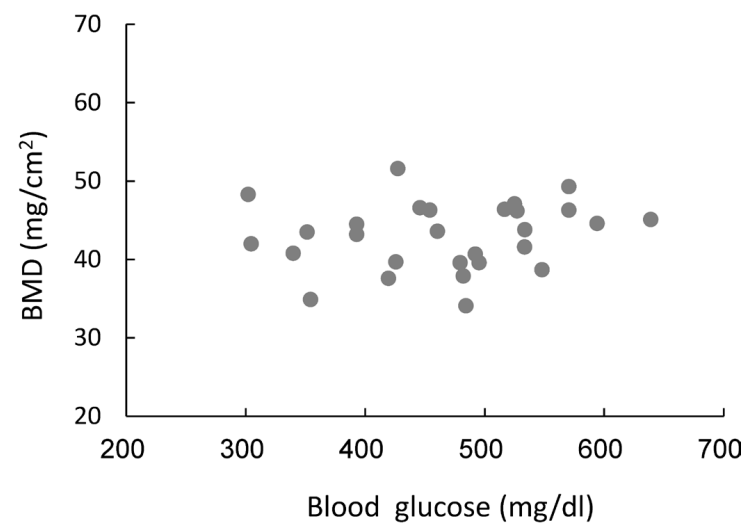

(b)

Fig. 8. Relationship between Blood Glucose Level and BMD of the Femur

There is a significant negative correlation between blood glucose level and BMD of the proximal region of the femur $(r=-0.64, p<0.05)$ (a). There is no significant correlation between blood glucose level and BMD of the mid-diaphysis $(r=0.16)(b)$.

et $a l .{ }^{33)}$ considered a change of BMD in the metaphysis of the femur using micro-CT in MKR mice, a non-obese transgenic mouse model of type 2 diabetes, and as a result, have shown that the femurs contained less cancellous bone in the proximal metaphysis through 3 to 16 weeks of age compared with the controls. Fujii et al. ${ }^{32)}$ have shown using DXA that in spontaneously diabetic Torii (SDT) rats, a model of non-obese type 2 diabetes, the BMD of the femur was significantly lower at 36 weeks of age compared with that in non-diabetics.

These studies have shown that the BMD of the metaphysis of the femur commonly decreases in type 2 diabetes, even though different kinds of diabetic animal models were used and the weeks of age at which BMD was measured were different in each study. We also found decreased BMD in the proximal metaphyseal region of the femur in our investigation, agreeing with the results of those studies. It is known that the metaphysis has more spongy bone than cortical bone while the diaphysis consists almost entirely of cortical bone. Therefore type 2 diabetes might affect the decrease of spongy bone. On the other hand, we could not find any significant difference in the mid-diaphysis with either week of age or in comparison with the controls, whereas a few studies have shown decreased BMD in both metaphysis and diaphysis. ${ }^{32,34)}$ The KKAy mouse is well known as a type 2 diabetes animal model to show insulin resistance and hyperglycemia with week of age, and obesity and hyperinsulinemia are its characteristics. ${ }^{43,44)}$ It may be necessary to consider species specificity with respect to the characteristics of BMD in the femur.

We then tried to observe the relationship between blood osteocalcin level and BMD, because it has been suggested that a decrease in blood osteocalcin level in both type 1 and type 2 diabetic animal models is one of the causes of BMD reduction. ${ }^{36,38)}$ In clinical analysis, Akin et $a l .{ }^{35)}$ have shown that blood osteocalcin level in type 2 diabetes was significantly lower than that in non-diabetics. Suzuki et al. ${ }^{37)}$ have also shown that blood osteocalcin level in male type 2 diabetes was significantly low. However the time of its determination varied in each study so that the time of decreases was not clear, though there are a few studies using animal models that show that it decreases from the early stage of diabetes, which is within five weeks from onset. ${ }^{18,36)}$ The association with the time when BMD decreases has not been clarified, either. We found a lower blood osteocalcin level at 18 weeks old when the BMD of the proximal region was low, whereas there was no significant difference at 8 weeks old. Accordingly, blood osteocalcin level does not necessarily show a low value at the early stage of diabetes, and it is thought that a reduction of blood osteocalcin level with week of age contributes to BMD reduction. On the other hand, it has been suggested that blood osteocalcin level is affected by hyperglycemia per se and may not correctly reflect bone turnover. ${ }^{45)}$ Verhaeghe et al. ${ }^{39)}$ have shown that hyperglycemia suppresses the function of osteoblast, and Terada et al. ${ }^{46)}$ have also shown that the proliferation and differentiation potency of osteoblast is inhibited by high glucose culture media in in vitro study.

Finally, we asked whether hyperglycemia was concerned in the decreased BMD or blood osteocalcin level. In fact, we found an increased blood glucose level at the same period as the BMD of the proximal region decreased, and this was also the same period as the blood osteocalcin level decreased in our study. As a result of the study, it seems that there are mutual associations among BMD, blood osteocalcin, and blood glucose levels. Further investigations are necessary to clarify the relationships between them. Some studies have shown that the longer the duration of diabetes the more BMD decreases, particularly in spongy bone, ${ }^{42,47,48)}$ whereas some other studies have shown that BMD has already decreased in the early stage of diabetes. ${ }^{31,33,34)}$ The result of this study may agree with the former, because BMD decreased not at 8 weeks old but after 18 weeks old, though the blood glucose level at 8 weeks old in KK-Ay mice was already significantly higher than that in $\mathrm{ddY}$ mice. So it is thought that it is the long duration of hyperglycemia and the progression of diabetes that cause BMD reduction. It has been shown that glycemic control may improve osteoblast function $^{49)}$ and protect type 2 diabetic patients from bone loss. ${ }^{25)}$ Ishida et $a l .{ }^{50)}$ have shown that insulin treatment normalizes blood osteocalcin level using laboratory animals, streptozotocin-induced diabetic rats (STZ rats). Accordingly it is very important to inhibit hyperglycemia to preserve osteoblast function and BMD in diabetes mellitus.

However there are a few limitations to this study. Firstly the limitation of DXA has been suggested because its accuracy 
in mice may be impaired due to them being too small ${ }^{51)}$ and also it is unsuitable for longitudinal investigations on mouse bone. ${ }^{52)}$ Therefore attention may need to be paid to this, even though all the measurements were carried out by the same radiological technologist in this study. Secondly we only determined the osteoplastic marker. It has been reported that in type 2 diabetes bone volume and the parameters for bone formation are decreased by oxidative stress due to hyperglycemia, ${ }^{16,32)}$ and advanced glycation end products (AGEs) cause degradation of osseous quality. ${ }^{53)}$ Therefore it will be necessary to consider some other factors.

In summary, our study has clarified the characteristics of diabetic osteopenia in laboratory KK-Ay diabetic mice. The BMD of the femur decreased with week of age after 18 weeks old, and occurred in the proximal region, not the mid-diaphysis. That is to say type 2 diabetes mellitus may exert an influence on spongy bone, whereas there was no influence on cortical bone. Blood osteocalcin level also decreased at the same time as BMD decreased and so was thought to contribute to $\mathrm{BMD}$ reduction. As the BMD in the proximal region showed a negative correlation with blood glucose level, BMD may decrease parallel with the progression of diabetes. Consequently it seemed that the BMD of the proximal region of the femur was affected by blood glucose level through blood osteocalcin. It is very important to control blood glucose level from the early stage of diabetes mellitus to prevent BMD reduction, and thus the risk of fractures. Further investigations will be necessary to clarify the mechanism of BMD reduction considering other factors such as osteoclast markers, insulin sensitivity, oxidative stress and so on because the importance of osseous quality, not only BMD, has been suggested in preventing the risk of fractures in type 2 diabetes.

\section{REFERENCES}

1) Ohkubo $Y$, Kishikawa H, Araki E, Miyata T, Isami S, Motoyoshi S, Kojima Y, Furuyoshi N, Shichiri M. Intensive insulin therapy prevents the progression of diabetic microvascular complications in Japanese patients with non-insulin-dependent diabetes mellitus: a randomized prospective 6-year study. Diabetes Res. Clin. Pract., 28, 103-117 (1995).

2) The Diabetes Control and Complications Trial Research Group. The effect of intensive treatment of diabetes on the development and progression of long-term complications in insulin-dependent diabetes mellitus. N. Engl. J. Med., 329, 977-986 (1993).

3) UK Prospective Diabetes Study (UKPDS) Group. Intensive bloodglucose control with sulphonylureas or insulin compared with conventional treatment and risk of complications in patients with type 2 diabetes (UKPDS 33). Lancet, 352, 837-853 (1998).

4) Chen HF, Ho CA, Li CY. Increased risks of hip fracture in diabetic patients of Taiwan: a population-based study. Diabetes Care, 31, $75-80$ (2008).

5) Hui SL, Epstein S, Johnston CC Jr. A prospective study of bone mass in patients with type I diabetes. J. Clin. Endocrinol. Metab., 60, 74-80 (1985).

6) Janghorbani M, Van Dam RM, Willett WC, Hu FB. Systematic review of type 1 and type 2 diabetes mellitus and risk of fracture. Am. J. Epidemiol., 166, 495-505 (2007).

7) Nicodemus KK, Folsom AR, Iowa Women's Health Study. Type 1 and type 2 diabetes and incident hip fractures in postmenopausal women. Diabetes Care, 24, 1192 -1197 (2001).

8) Schwartz AV, Sellmeyer DE, Ensrud KE, Cauley JA, Tabor HK, Schreiner PJ, Jamal SA, Black DM, Cummings SR, Study of
Osteoporotic Features Research Group. Older women with diabetes have an increased risk of fracture: a prospective study. J. Clin. Endocrinol. Metab., 86, 32-38 (2001).

9) Vestergaard P, Rejnmark L, Mosekilde L. Relative fracture risk in patients with diabetes mellitus, and the impact of insulin and oral antidiabetic medication on relative fracture risk. Diabetologia, 48, 1292-1299 (2005).

10) Vestergaard P. Discrepancies in bone mineral density and fracture risk in patients with type 1 and type 2 diabetes - a meta-analysis. Osteoporos. Int., 18, 427-444 (2007).

11) Yamamoto $M$, Yamaguchi $T$, Yamauchi $M$, Kaji H, Sugimoto $T$. Bone mineral density is not sensitive enough to assess the risk of vertebral fractures in type 2 diabetic women. Calcif. Tissue Int., 80, $353-358$ (2007).

12) Miazgowski $T$, Czekalski S. A 2-year follow-up study on bone mineral density and markers of bone turnover in patients with longstanding insulin-dependent diabetes mellitus. Osteoporos. Int., 8, 399-403 (1998).

13) Muñoz-Torres M, Jódar E, Escobar-Jiménez F, López-Ibarra PJ, Luna JD. Bone mineral density measured by dual X-ray absorptiometry in Spanish patients with insulin-dependent diabetes mellitus. Calcif. Tissue Int., 58, 316-319 (1996).

14) Strotmeyer ES, Cauley JA, Orchard TJ, Steenkiste AR, Dorman JS. Middle-aged premenopausal women with type 1 diabetes have lower bone mineral density and calcaneal quantitative ultrasound than nondiabetic women. Diabetes Care, 29, 306-311 (2006).

15) Tuominen JT, Impivaara O, Puukka P, Rönnemaa T. Bone mineral density in patients with type 1 and type 2 diabetes. Diabetes Care, 22, 1196-1200 (1999).

16) Hamada Y, Kitazawa S, Kitazawa R, Fujii H, Kasuga M, Fukagawa M. Histomorphometric analysis of diabetic osteopenia in streptozotocin-induced diabetic mice: a possible role of oxidative stress. Bone, 40, 1408-1414 (2007).

17) Silva MJ, Brodt MD, Lynch MA, McKenzie JA, Tanouye KM, Nyman JS, Wang X. Type 1 diabetes in young rats leads to progressive trabecular bone loss, cessation of cortical bone growth, and diminished whole bone strength and fatigue life. J. Bone Miner. Res., 24, 1618-1627 (2009).

18) Verhaeghe J, Visser WJ, Einhorn TA, Bouillon R. Osteoporosis and diabetes: lessons from the diabetic BB rat. Horm. Res., 34, 245-248 (1990).

19) Verhaeghe J, van Herck E, Visser WJ, Suiker AM, Thomasset M, Einhorn TA, Faierman E, Bouillon R. Bone and mineral metabolism in $\mathrm{BB}$ rats with long-term diabetes. Decreased bone turnover and osteoporosis. Diabetes, 39, 477-482 (1990).

20) Petit MA, Paudel ML, Taylor BC, Hughes JM, Strotmeyer ES, Schwartz AV, Cauley JA, Zmuda JM, Hoffman AR, Ensrud KE, Osteoporotic Fractures in Men (MrOs) Study Group. Bone mass and strength in older men with type 2 diabetes: the Osteoporotic Fractures in Men Study. J. Bone Miner. Res., 25, 285-291 (2010).

21) Schwartz AV, Sellmeyer DE. Women, type 2 diabetes, and fracture risk. Curr. Diab. Rep., 4, 364-369 (2004).

22) Strotmeyer ES, Cauley JA, Schwartz AV, Nevitt MC, Resnick HE, Zmuda JM, Bauer DC, Tylavsky FA, de Rekeneire N, Harris TB, Newman AB, Health ABC, Health ABC Study. Diabetes is associated independently of body composition with BMD and bone volume in older white and black men and women: The Health, Aging, and Body Composition Study. J. Bone Miner. Res., 19, 1084-1091 (2004).

23) van Daele PL, Stolk RP, Burger H, Algra D, Grobbee DE, Hofman A, Birkenhäger JC, Pols HA. Bone density in non-insulin-dependent diabetes mellitus. The Rotterdam Study. Ann. Intern. Med., 122, 409-414 (1995).

24) Yamamoto $M$, Yamaguchi $T$, Yamauchi $M$, Kaji H, Sugimoto $T$. Diabetic patients have an increased risk of vertebral fractures independent of BMD or diabetic complications. J. Bone Miner. Res., 24, $702-709$ (2009). 
25) Buysschaert M, Cauwe F, Jamart J, Brichant C, De Coster P, Magnan A, Donckier J. Proximal femur density in types 1 and 2 diabetic patients. Diabete Metab., 18, 32-37 (1992).

26) Gregorio F, Cristallini S, Santeusanio F, Filipponi P, Fumelli P. Osteopenia associated with non-insulin-dependent diabetes mellitus: what are the causes? Diabetes Res. Clin. Pract., 23, 43-54 (1994).

27) Isaia G, Bodrato L, Carlevatto V, Mussetta M, Salamano G, Molinatti GM. Osteoporosis in type II diabetes. Acta Diabetol. Lat., 24, 305-310 (1987).

28) Ishida H, Seino Y, Matsukura S, Ikeda M, Yawata M, Yamashita G, Ishizuka S, Imura H. Diabetic osteopenia and circulating levels of vitamin D metabolites in type 2 (noninsulin-dependent) diabetes. Metabolism, 34, 797-801 (1985).

29) Levin ME, Boisseau VC, Avioli LV. Effects of diabetes mellitus on bone mass in juvenile and adult-onset diabetes. N. Engl. J. Med., 294, 241-245 (1976).

30) Seino $Y$, Ishida $H$, Imura $H$, Akazawa $Y$, Aochi $O$, Hamada $S$, Horiuchi N, Hoshi M, Ikeda M, Igarashi T, Izumi K, Kanatsuna T, Kido H, Matsukura S, Matsuoka A, Miyamura K, Morita T, Mozai T, Nanbu S, Nannjo K, Nonaka K, Ohsawa A, Ohtsuka A, Sako Y, Seino Y, Seki J, Shichiri M, Shigeta Y, Shima K, Yamamoto M, Yawata M. Diabetic osteopenia in central Japan. Diabete Metab., 11, 216-219 (1985).

31) Amir G, Rosenmann E, Sherman Y, Greenfeld Z, Ne'eman Z, Cohen AM. Osteoporosis in the Cohen diabetic rat: correlation between histomorphometric changes in bone and microangiopathy. Lab. Invest., 82, 1399-1405 (2002).

32) Fujii H, Hamada Y, Fukagawa M. Bone formation in spontaneously diabetic Torii-newly established model of non-obese type 2 diabetes rats. Bone, 42, 372-379 (2008).

33) Kawashima Y, Fritton JC, Yakar S, Epstein S, Schaffler MB, Jepsen KJ, LeRoith D. Type 2 diabetic mice demonstrate slender long bones with increased fragility secondary to increased osteoclastogenesis. Bone, 44, 648-655 (2009).

34) Lorentzon R, Alehagen U, Boquist L. Osteopenia in mice with genetic diabetes. Diabetes Res. Clin. Pract., 2, 157-163 (1986).

35) Akin O, Göl K, Aktürk M, Erkaya S. Evaluation of bone turnover in postmenopausal patients with type 2 diabetes mellitus using biochemical markers and bone mineral density measurements. Gynecol. Endocrinol., 17, 19-29 (2003).

36) Ishida $H$, Seino $Y$, Taminato $T$, Usami M, Takeshita N, Seino $Y$, Tsutsumi C, Moriuchi S, Akiyama Y, Hara K. Circulating levels and bone contents of bone gamma-carboxyglutamic acid-containing protein are decreased in streptozocin-induced diabetes. Possible marker for diabetic osteopenia. Diabetes, 37, 702-706 (1988).

37) Suzuki K, Kurose T, Takizawa M, Maruyama M, Ushikawa K, Kikuyama M, Sugimoto C, Seino Y, Nagamatsu S, Ishida H. Osteoclastic function is accelerated in male patients with type 2 diabetes mellitus: the preventive role of osteoclastogenesis inhibitory factor/osteoprotegerin (OCIF/OPG) on the decrease of bone mineral density. Diabetes Res. Clin. Pract., 68, 117-125 (2005).

38) Takeshita N, Ishida $H$, Yamamoto $T$, Koh G, Kurose $T$, Tsuji K, Okamoto Y, Ikeda H, Seino Y. Circulating levels and bone con- tents of bone gamma-carboxyglutamic acid-containing protein in rat models of non-insulin-dependent diabetes mellitus. Acta Endocrinol. (Copenh.), 128, 69-73 (1993).

39) Verhaeghe J, Suiker AM, Nyomba BL, Visser WJ, Einhorn TA, Dequeker J, Bouillon R. Bone mineral homeostasis in spontaneously diabetic BB rats. II. Impaired bone turnover and decreased osteocalcin synthesis. Endocrinology, 124, 573-582 (1989).

40) Marks V, Lloyd K. Preservation of blood glucose analysis by glucose oxidase. Clin. Chim. Acta, 8, 326 (1963).

41) Bridges MJ, Moochhala SH, Barbour J, Kelly CA. Influence of diabetes on peripheral bone mineral density in men: a controlled study. Acta Diabetol., 42, 82-86 (2005).

42) Wakasugi M, Wakao R, Tawata M, Gan N, Koizumi K, Onaya T. Bone mineral density measured by dual energy X-ray absorptiometry in patients with non-insulin-dependent diabetes mellitus. Bone, 14, 29-33 (1993).

43) Nakamura M. A diabetic strain of the mouse. Proc. Jpn. Acad., 38, 348-352 (1962).

44) Nishimura M. Breeding of mice strains for diabetes mellitus. Exp. Anim., 18, 147-157 (1969).

45) Okazaki R, Totsuka Y, Hamano K, Ajima M, Miura M, Hirota Y, Hata K, Fukumoto S, Matsumoto T. Metabolic improvement of poorly controlled noninsulin-dependent diabetes mellitus decreases bone turnover. J. Clin. Endocrinol. Metab., 82, 2915-2920 (1997).

46) Terada $M$, Inaba $M$, Yano $Y$, Hasuma $T$, Nishizawa $Y$, Morii $H$, Otani S. Growth-inhibitory effect of a high glucose concentration on osteoblast-like cells. Bone, 22, 17-23 (1998).

47) Einhorn TA, Boskey AL, Gundberg CM, Vigorita VJ, Devlin VJ, Beyer MM. The mineral and mechanical properties of bone in chronic experimental diabetes. J. Orthop. Res., 6, 317-323 (1988).

48) Kayath MJ, Tavares EF, Dib SA, Vieira JG. Prospective bone mineral density evaluation in patients with insulin-dependent diabetes mellitus. J. Diabetes Complications, 12, 133-139 (1998).

49) Sayinalp S, Gedik O, Koray Z. Increasing serum osteocalcin after glycemic control in diabetic men. Calcif. Tissue Int., 57, 422-425 (1995).

50) Ishida H, Seino Y, Takeshita N, Kurose T, Tsuji K, Okamoto Y, Someya Y, Hara K, Akiyama Y, Imura H, Nozawa M. Effect of pancreas transplantation on decreased levels of circulating bone gamma-carboxyglutamic acid-containing protein and osteopenia in rats with streptozotocin-induced diabetes. Acta Endocrinol. (Copenh.), 127, 81-85 (1992).

51) Tsujio M, Mizorogi T, Kitamura I, Maeda Y, Nishijima K, Kuwahara S, Ohno T, Niida S, Nagaya M, Saito R, Tanaka S. Bone mineral analysis through dual energy X-ray absorptiometry in laboratory animals. J. Vet. Med. Sci., 71, 1493-1497 (2009).

52) Dickson GR, Luczak M, Włodarski KH. The limitation of DEXA analysis for bone mass determination in mice. Folia Biol. (Krakow), 52, 125-129 (2004).

53) Saito M, Fujii K, Mori Y, Marumo K. Role of collagen enzymatic and glycation induced cross-links as a determinant of bone quality in spontaneously diabetic WBN/Kob rats. Osteoporos. Int., 17, $1514-1523$ (2006) 